\title{
Estimating sample representativeness in a survey of stream caddis- fly fauna
}

\author{
D. Schmera ${ }^{*}$, T. Eros ${ }^{2}$ \\ 1 Plant Protection Institute, Hungarian Academy of Sciences, H-1525 Budapest, POB. 102, Hungary \\ ${ }^{2}$ Balaton Limnological Research Institute, Hungarian Academy of Sciences, H-8237 Tihany, Klebelsberg Kuno u. 3, Hungary
}

\begin{abstract}
Obtaining an adequate and representative sample is a continuing challenge of community ecology. The present study focuses on what sample area represents adequately the structural composition of the caddisfly fauna of a riffle, at a given sampling occasion. Sixty-two Surber samples were collected from a riffle in a second-order reach of the Bernecei Stream (Börzsöny Mountains, Hungary). This data set was used to estimate sample representativeness at different sample sizes (from 1 to 31 Surber samples, $0.09 \mathrm{~m}^{2}-2.79 \mathrm{~m}^{2}$ ) generated a re-sampling procedure. Sample representativeness was measured with mean Jaccard Coefficient and Bray-Curtis Index between samples for species presence-absence data and abundance data, respectively. We found that a sample size of $2.25 \mathrm{~m}^{2}$ represented well (mean similarity 0.998 ) the species composition of the caddisfly fauna if rare species were excluded from the analysis. In contrast, sample representativeness of species composition proved to be relatively low (0.719) if rare species were included in the analysis. Curves of sample representativeness based on both raw-, or transformed abundance data were less sensitive to the presence of rare species and showed lower representativeness than sample representativeness based on presence/absence data.
\end{abstract}

Keywords: Trichoptera, sample representativeness, stream fauna, sampling, riffle

\section{Introduction}

Obtaining an adequate sample of ecological communities is the first step towards interpreting spatial and temporal variability of community organization (Bady et al. 2005). From a statistical point of view, the adequateness of a sample can be characterized by its accuracy and precision. Accuracy is the nearness of a measurement to the actual value of the variable being measured, while precision refers to the closeness to each other of repeated measurements of the same quality (Zar 1999). In most cases, we do not know the actual value of the variable studied, thus accuracy cannot be measured. In contrast, precision can be expressed by comparing repeated measurements of the same quality. It is the basic idea in the development of the term sample representativeness (Cao et al. 2002a, 2002b), a term used to describe how well a sample represents the community. In order to measure representativeness, two samples are collected from the same community and a measure of the similarity (or autosimilarity Cao et al. 2003) determined. If the similarity between the

* Corresponding author : E-mail : schmera@ julia-nki.hu samples is high, the samples give a good representation of the community (i.e. with great precision), whilst a low index value refers to inadequate sample representativeness.

Several factors might influence the representativeness of a sample however (e.g. Statzner et al. 1998). For example, inclusion or exclusion of rare species (Gaston 1994) into analyses is a permanent question for community ecology and bioassessment. Some authors advocate the use of rare species in community analyses (Cao et al. 1998, 2001, Nijboer \& SchmidtKloiber 2004) whilst others argue against it (Marchant 1999, 2002). Although the question of including or excluding rare species is largely dependent on the analyses, most researchers share the view that inclusion of rare species causes large sampling error (Bradley \& Ormerod 2002) and decreases precision (Ostermiller \& Hawkins 2004), in evaluating community structure of stream macroinvertebrates.

Most researchers consider physical habitat as the major determinant of faunal organization in running waters (Allan 1995, Giller \& Malmqvist 1998) and thus, examine community organization within and among levels of a nested habitat hierarchy (Minshall 1988, Li et al. 2001, Wright \& Li 2002, Weigel et al. 
2003, Townsend et al. 2003, 2004). In this paper, we followed the suggestion of Noda (2004), and used the term scale, as the physical dimension of the sample (for instance, the total sampled area) and the term level, as the spatial range of the study. Thus, we considered microhabitat, pool/riffle, reach, segment, and stream system as different levels of a habitat hierarchy (Frissell et al. 1986). Since the level of riffle-pool is generally considered as a building block of the upper levels of habitat hierarchy (e.g. reach, catchment or ecoregion (Weigel et al. 2003, Sandin \& Johnson 2004, Verdonschot \& Nijboer 2004)), obtaining an adequate sample from a riffle has fundamental importance to interpreting the community organization of stream macroinvertebrates at upper levels of spatial habitat hierarchy (Boyero 2003, Hering et al. 2004). Although studies on sample representativeness do exist at the reach level (Cao et al. 2002a, b; 2003), according to our knowledge, nobody has examined which size of sample adequately represents the riffle macroinvertebrate community.

In the present study we examined how the representativeness of a caddisfly assemblage varied with increasing sampling effort (i.e. increasing sample size) in a riffle using the recently developed similarity-based approach of Cao et al. (2002a). We also tested how sampling representativeness varies with the inclusion, or exclusion of rare species. Caddisflies were selected as study organisms as they form an abundant and species-rich group in the macroinvertebrate communities of headwater streams (Allan 1995, Giller \& Malmqvist 1998) and taxonomic keys for species-level identification (Waringer \& Graf 1997) are available. The answer of these questions is of basic importance to the design of ecological studies examining the aquatic fauna of streams at the riffle or upper levels of spatial habitat hierarchy.

\section{Material and Methods}

\section{Study area and field sampling}

The study was carried out in the Bernecei stream, a second order stream in the Börzsöny Mountains, Hungary (see Fig 1 in Eros \& Grossman 2005). The stream meanders through an oak-hornbeam woodland (Querco-Carpinetum) with riparian vegetation dominated by alder (Alnus glutinosa). The canopy provides extensive shading and leaves little light for instream primary production. Hence, matter production was predominantly based on allochthonous leaf litter from the surrounding riparian vegetation. The stream has a well-developed riffle-pool morphology with cobble and gravel as the dominant substratum, and is representative of the natural submountane streams of the Carpathian region in Central Europe (Eros et al. 2003, Schmera \& Eros 2004).

Based upon previous studies (Schmera 2004, Schmera \& Eros 2004), a riffle (length $13 \mathrm{~m}$, average width $4.1 \mathrm{~m})$ was selected in the stream $\left(47^{\circ} 58^{\prime} 03^{\prime \prime} \mathrm{N}\right.$, $18^{\circ} 55^{\prime} 02^{\prime \prime} \mathrm{E}, 188 \mathrm{~m}$ a.s.l.). The water depth within the riffle varied between 3 and $8 \mathrm{~cm}$. The dominant substrate was cobbles $(70 \%)$ with gravel $(25 \%)$ (Giller \& Malmqvist 1998) and the diameter of the particles varied between 4 and $8 \mathrm{~cm}$. Caddisfly larvae were collected on 18 May 2004 using a standardized Surber sampler (area: $0.09 \mathrm{~m}^{2}$, mesh size: $0.5 \mathrm{~mm}$ ). Although the riffle was well shaded, there was not any significant accumulation of coarse particulate organic matter that would have favoured the aggregation of shredders (Hildrew et al. 1991, Murphy et al. 1998, Dobson 1999, Muotka \& Laasonen 2002). Consequently, the riffle was considered to present a relative homogeneous environment for stream dwelling caddisflies. Before sampling, the riffle was mapped and the position of each of the 62 Surber samples was chosen randomly. Sampling began downstream to avoid disturbance to the upstream sector of the riffle. To dislodge caddisflies from the substrate and allow the streamflow to carry them into the Surber net, the substrate within the quadrat frame of the Surber sampler was agitated by hand to a depth of about $5 \mathrm{~cm}$, followed by careful examination of all cobble and gravel clasts. Each sample was preserved separately in 5\% formalin, labelled and returned to the laboratory for examination. Caddisflies were identified using Waringer \& Graf (1997).

\section{Data processing and statistical analyses}

Initially each Surber sample was regarded as a sample unit. These were then pooled to generate increasing sample size (Cao et al. 2002a). Accordingly, a sample can be characterized by its sample size (i.e. number of sample units pooled or more generally by the pooled sample area in square meters). Sample representativeness was expressed as the similarity between two samples. High similarity means adequate representativeness, while low index value an inadequate one. We used two commonly used similarity indices (Cao et al. 2002b, Podani 2000), the Jaccard index $(J C)$ and the Bray-Curtis index $(B C)$.

$$
J C=\frac{a}{a+b+c}, B C=1-\frac{\sum\left|x_{i j}-x_{k j}\right|}{\sum\left(x_{i j}+x_{k j}\right)}
$$


where $a$ is the number of species present in both samples, $b$ is the number of species present only in the first sample, $c$ is the number of species present only in the second sample; $x_{j i}$ is the abundance of species $j$ in sample $i$, and $x_{k j}$ is the abundance of the species $j$ in sample $k . J C$ was used to examine similarity in species composition using presence/absence data, whilst $B C$ uses abundance data. $B C$ was used with raw abundance and $\log (x+1)$ transformed abundance data (hereafter called as raw abundance and transformed abundance data).

Altogether 31 sample sizes were examined (from $0.09 \mathrm{~m}^{2}=1$ sample unit to $2.79 \mathrm{~m}^{2}=31$ sample units pooled). An even number of sample units were drawn randomly from the total 62 sample units $(n \times 2$, where $n$ is the number of sample units pooled from 1 to 31 ). The first $n$ sample units were pooled to create a new sample, the other $n$ units were then used to form another new sample so that the pair of new samples shared no sample units. Both indices (JC and BC) were then calculated for the pair of new samples. This process was repeated 1000 times to obtain mean $J C$ and mean $B C$ for each level of sample size and for each data set. In addition, the indices were calculated by including and excluding rare species (number of occurrence/abundance equal or less than 5 using species lists/abundances). The similarity values generated in the resulting matrix were compared with a hypothetical value of 1 (100\% similarity) or perfect representativeness. Comparison was performed using a $p$ value. The $p$ value expresses the proportion of the similarity index values that were equal to the hypothesised similarity value (Manly 1991). The similarity index was deemed significant if the $p$-value was equal or less than 0.05 .

\section{Results}

Altogether 716 individuals belonging to 13 species were identified (Table 1). The number of species among sample units varied between 0 (only in a single sample unit) and 6 (mean $M=2.677$, standard deviation $S D=1.211$ ), whilst the number of individuals ranged between 0 and $52(M=11.548, S D=11.707)$. Excluding rare species resulted in analyses using 6 species (presence/absence data) or 8 species (abundance data) only.

In general, curves showed a better representativeness at larger sample sizes forming typical accumulation curves (Fig. 1, 2 and 3). In case of presence/absence data (Fig. 1), a mean similarity of 0.391 and 0.441 was observed at the smallest sample size (1 Surber sample, $0.09 \mathrm{~m}^{2}$ ) if rare species were included or excluded, respectively. At the largest sample size (31 Surber sample, $2.79 \mathrm{~m}^{2}$ ), the mean similarity values were 0.719 and 0.998 , respectively. Representativeness of presence/absence data without rare species was always higher than that including rare species (Fig. 1). We observed perfect representativeness $(100 \%$ similarity at $p$ $=0.05)$ only when rare species were excluded and at large sample sizes (25-31 Surber samples, $2.25 \mathrm{~m}^{2}$ $\left.2.79 \mathrm{~m}^{2}\right)$.

Table 1. The list of species and their occurrence and abundance

\begin{tabular}{|c|c|c|}
\hline Species & $\begin{array}{l}\text { Number of } \\
\text { occurrences }\end{array}$ & $\begin{array}{c}\text { Pooled } \\
\text { abundance }\end{array}$ \\
\hline \multicolumn{3}{|l|}{ Rhyacophilidae } \\
\hline Rhyacophila fasciata Hagen, 1859 & 18 & 39 \\
\hline Rhyacophila nubila (Zetterstedt, 1840) & 2 & 2 \\
\hline \multicolumn{3}{|l|}{ Glossosomatidae } \\
\hline Synagapetus moselyi Ulmer, 1938 & 15 & 31 \\
\hline \multicolumn{3}{|l|}{ Hydropsychidae } \\
\hline Hydropsyche instabilis Curtis, $1834^{\circ}$ & 5 & 6 \\
\hline Hydropsyche saxonica McLachlan, 1884 & 5 & 5 \\
\hline \multicolumn{3}{|l|}{ Polycentropodidae } \\
\hline Cyrnus trimaculatus (Curtis, 1834) & 1 & 1 \\
\hline \multicolumn{3}{|l|}{ Limnephilidae } \\
\hline Limnephilus lunatus Curtis, 1834 & 1 & 1 \\
\hline Anabolia furcata Brauer, 1857 & 8 & 20 \\
\hline Potamophylax rotundipennis (Brauer, 1857) & 55 & 488 \\
\hline Halesus digitatus (Schrank, 1781) & 42 & 104 \\
\hline Halesus tesselatus (Rambur, 1842) & 8 & 11 \\
\hline Micropterna nycterobia McLachlan, 1875 & 1 & 1 \\
\hline \multicolumn{3}{|l|}{ Leptoceridae } \\
\hline Athripsodes bilineatus (Linnaeus, 1758) & 5 & 7 \\
\hline
\end{tabular}

In case of transformed abundance data (Fig. 2), a mean similarity of 0.422 and 0.439 was observed at the smallest sample size (1 Surber sample), rare species included or excluded, respectively. At the largest sample size (31 Surber samples), the mean similarity values were 0.854 and 0.901 . In case of raw abundance data (Fig. 3), a mean similarity of 0.320 and 0.334 at $0.09 \mathrm{~m}^{2}$ sample size (1 Surber sample), rare species included or excluded, respectively was observed. At the largest sample size, the mean similarity values were 0.827 and 0.836, respectively. Consequently, in contrast to presence/absence data the curves based on raw or transformed abundance data did not reach the asymptote (i.e. perfect representativeness was not observed). The mean similarity values were generally of similar characteristics, independently of whether rare species were included or excluded in the analysis. Ho- 
wever, analysis based on transformed abundance data was more sensitive to inclusion-exclusion of rare species than analysis based on raw abundance data (Fig. 2, $3)$.

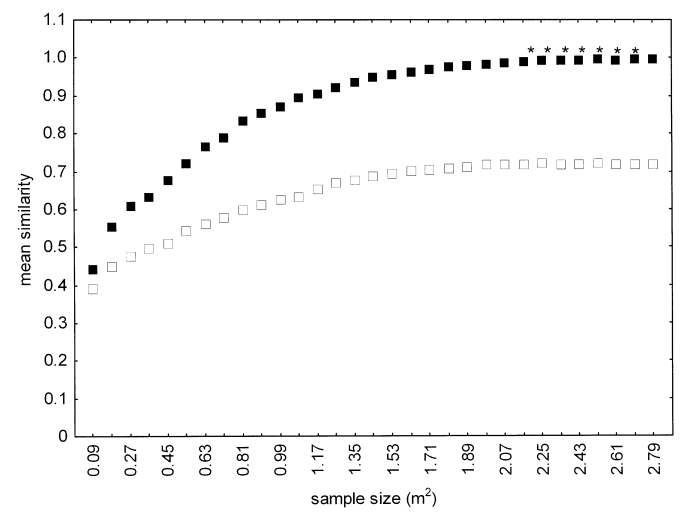

Fig. 1. The relationship between sample size and similarity of samples based on presence/absence data (Jaccard index, full squares: rare species excluded, open squares: rare species included, asterisks show non-significant differences from 1 at $p=0.05$ )

Comparison of the presence/absence, transformed abundance and raw abundance curves was rather problematic because of their different sensitivity to species abundance. At the smallest sample size $\left(0.09 \mathrm{~m}^{2}\right)$ the mean similarity of samples based on presence/absence data was higher compared to the mean similarity values based on transformed and raw abundance data. In contrast, at larger sample sizes (more than 1 Surber sample, $>0.09 \mathrm{~m}^{2}$ ) the mean similarity value of samples, excluding rare species and based on presence absence data, was the highest; this being followed by the values of the data sets based on transformed and raw abundance data and by values based on presence/absence data, that included rare species.

\section{Discussion}

Representative sampling is fundamental for the unbiased understanding of the spatial and temporal patterns of aquatic faunal organization. In the present study we examined how sample size and rare species influence representativeness of our samples and drew two fundamental conclusions. First, our study illustrated that in- or exclusion of rare species strongly influenced representativeness of the samples. Rare species might have high conservation importance (Schmera 2003, Schmera \& Kiss 2004) and often represent "Red List" species (Nógrádi \& Uherkovich 1999). Moreover, rare species might be keystone species with disproportionately important roles in influencing community structure and the flow of energy and nutrients through the community (Palmer et al. 1997, Creed \& Reed 2004), thus providing valuable conservation tools and, therefore - according to our view - justify a somewhat lowered precision in applied studies. Second, our results showed that sample representativeness was strongly depended upon the size of the sample. The results of this study support those of Statzner (1981), who found that several-hundred sample units should be taken in a relatively homogeneous stream reach to evaluate the density of individual species. These results call attention to the application of more intensive sampling regimes in studying and/or assessing macroinvertebrate assemblages. For example, sample sizes used in macroinvertebrate studies of riffles $\left(0.2-0.4 \mathrm{~m}^{2}\right.$ total area sampled; see e.g. Boyero 2003, Heino et al. 2004, Schmera \& Eros 2004) may be insufficient to determine similarities or differences, since it is hard to decide at such a small sample size whether differences are real or artificial (i.e. caused by sampling error).

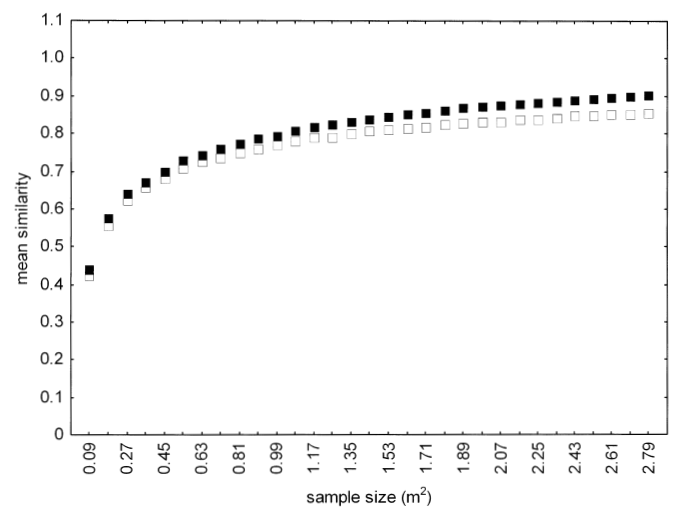

Fig. 2. The relationship between sample size and similarity of samples based on transformed abundance data $(\log (x+1)$ transformation, Bray-Curtis index, full squares: rare species excluded, open squares: rare species included)

Although our study did not aim to evaluate the sample size for detecting perturbation-induced impact (i.e. to separate natural communities from impaired ones), the natural spatial variability we observed (high sample size is needed to reach an acceptable level of sample representativeness, Figs. 1, 2 and 3) predicts relative large sample sizes for impact detection. If this assumption would receive support in the future, as at temperate lake macroinvertebrate communities (Johnson 1998), then sample sizes used in stream bioassess- 
ment protocols should carefully re-considered.

Although riffle-level variability in assemblage structure can contribute substantially to reach level variability (Downes et al. 2000), the contribution of the different levels of habitat hierarchy to the variability of macroinvertebrate assemblages is rather controversial (Hawkins et al. 2000, Townsend et al. 2003). Nevertheless, for the proper interpretation of macroinvertebrate organization at a level of habitat hierarchy it is important to note that the non-explained variability caused by error/residuals falls between $20-85 \%$ (Li et al. 2001, Boyero 2003, Heino et al. 2004), and can approach $100 \%$ (Boyero \& Bailey 2001). It means, that in most cases, the majority of the variance of community structural properties of stream macroinvertebrate cannot be explained. In addition, this is also the case, when categorical data are used for stream assessments, including functional feeding groups (Heino et al. 2004) or biotic indices (e.g. the EPT index, Boyero 2003). Obviously, all of these uncertainties might be caused by the unsuitable sample sizes used and the patchy distribution of macroinvertebrates in streams (Townsend 1989, Lake 2000).

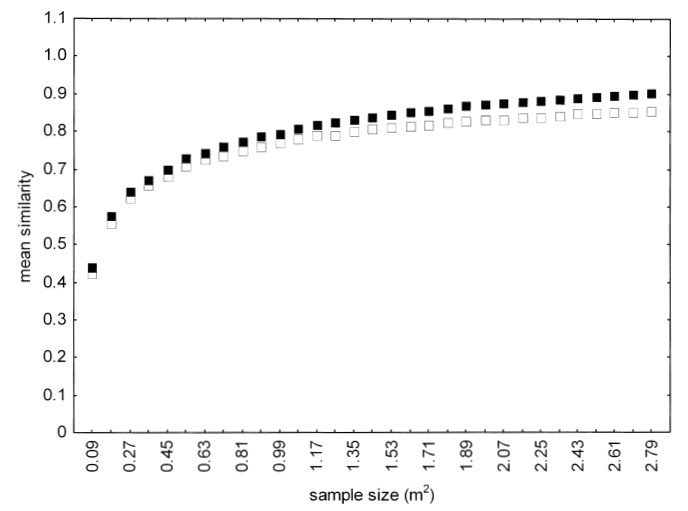

Fig. 3. The relationship between sample size and similarity of samples based on abundance data (raw abundance data, Bray-Curtis index, full squares: rare species excluded, open squares: rare species included)

It is important to note that several factors restrict the generalization of our conclusions. First, Surber samples deal with the topmost $5 \mathrm{~cm}$ of the substrate only. Consequently our species list might increase by applying another sampling technique (Waringer 1987, Weigelhofer \& Waringer 2003). Second, although conclusions drawn from this study are based on the examination of caddisflies, this group shows a considerable variability in assemblage structure amongst different aquatic habitats (Dohet 2002), and play a significant role in the dynamics of macroinvertebrate assemblages (Cardinale et al. 2001). In contrast, other studies suggest that different macroinvertebrate groups use more or less different habitats (Statzner et al. 1997), which may result in that sample size found to be relatively representative for assessing caddisfly assemblages is underestimated for the whole macroinvertebrate community. Third, only a single riffle was studied and macroinvertebrates show considerable variability among riffles (Downes et al 2000, Li et al. 2001, Boyero 2003, Heino et al. 2004). Nevertheless, the influence of rare species and sample size should have similar in tendency at other localities.

In summary, this study demonstrated that representativeness of a caddisfly assemblage along a riffle showed strong dependence upon the sample size: as sample size increased, the representativeness improved. Inclusion or exclusion of rare species influenced representativeness however, the effect of rare species strongly depended on the assemblage metric used.

\section{Acknowledgement}

We thank Árpád Szentesi, Malcolm T. Greenwood and two anonymous referees for their comments on the manuscript. This research was financially supported by the Bolyai Scholarship of the Hungarian Academy of Sciences.

\section{References}

Allan J.D. 1995. - Stream ecology: Structure and function of running waters. Chapman \& Hall, London

Bady P., Doledec S., Fesl C., Gayraud S., Bacchi M. \& Schöll F. 2005. - Use of invertebrate traits for the monitoring of European large rivers: the effects of sampling effort on genus richness and functional diversity. Freshwater Biol., 50, 159-173.

Boyero L. 2003. - Multiscale patterns of spatial variation in stream macroinvertebrate communities. Ecol. Res., 18, 365-379.

Boyero L. \& Bailey R.C. 2001. - Organization of macroinvertebrate communities at a hierarchy of spatial scales in a tropical stream. Hydrobiologia, 464, 219-225.

Bradley D.C. \& Ormerod S.J. 2002. - Evaluating the precision of kick-sampling in upland streams for assessments of long-term change: the effects of sampling effort, habitat and rarity. Archiv Hydrobiol., 155, 199-221.

Cao Y., Williams D.D. \& Williams N.E. 1998. - How important are rare species in aquatic ecology and bioassessment? Limnol. Oceanogr., 43, 1403-1409.

Cao Y., Larsen D.P. \& Thorne R. St-J. 2001. - Rare species in multivariate analysis for bioassessment: some considerations. J. N. Am. Benthol. Soc., 20, 144-153.

Cao Y., Williams D.D. \& Larsen D.P. 2002a. - Comparison of ecological communities: the problem of sample representativeness. Ecol. Monogr., 72, 41-56.

Cao Y., Larsen D.P., Hughes R.M., Angermeier P.L. \& Patton T.M. 2002b. - Sampling effort affects multivariate comparisons of stream assemblages. J. N. Am. Benthol. Soc., 21, 701-714.

Cao Y., Hawkins C.P. \& Vinson M.R. 2003. - Measuring and controlling data quality in biological assemblage surveys with 
special reference to stream benthic macroinvertebrates. Freshwater Biol., 48, 1898-1911.

Cardinale B.J., Smith C.M. \& Palmer M.A. 2001. - The influence of initial colonization by hydropsychid caddisfly larvae on the development of stream invertebrate assemblages. Hydrobiologia, 455, 19-27.

Creed R.P. \& Reed J.M. 2004. - Ecosystem engineering by crayfish in a headwater community. J. N. Am. Benthol. Soc., 3, 224-236.

Dobson M. 1999. - Aggregation of Potamophylax cingulatus (Trichoptera: Limnephilidae) larvae in response to possible food limitation in a southern French stream. Archiv Hydrobiol., 145, 317329.

Dohet A. 2002. - Are caddisflies an ideal group for the biological assessment of water quality in streams? Nova Suppl. Entomol., 15, 507-520.

Downes B.J., Hindell J.S \& Bond N.R. 2000. - What's in a site? Variation in lotic macroinvertebrate density and diversity in a spatially replicated experiment. Austral Ecol., 25, 128-139.

Eros T., Botta-Dukát Z. \& Grossman G.D. 2003. - Assemblage structure and habitat use of fishes in a Central European submontain stream: a patch-based approach. Ecol. Freshwat. Fish., 12, 141-150.

Eros T. \& Grossman G.D. 2005. - Fish biodiversity in two Hungarian streams: a landscape-based approach. Archiv Hydrobiol., 162, 5371.

Frissell C.A., Liss W.J., Warren C.E. \& Hurley M.D. 1986. - A hierarchical framework for stream habitat classification: viewing streams in a watershed context. Environ. Manageme., 10, 199214.

Gaston K.J. 1994. - Rarity. Population and community biology series 13. Chapman \& Hall, London

Giller P.S. \& Malmqvist B. 1998. - The biology of streams and rivers. Oxford University Press, Oxford

Hawkins C.P., Norris R.H., Gerristen J., Hughes R.M., Jackson S.K., Johnson R.K. \& Stevenson R.J. 2000. - Evaluation of landscape classifications for biological assessment for freshwater ecosystems: synthesis and recommendations. J. N. Am. Benthol. Soc., 19, 541-556.

Heino J., Louhi P. \& Muotka T. 2004. - Identifying the scales of variability in stream macroinvertebrate abundance, functional composition and assemblage structure. Freshwater Biol., 49: 12301239.

Hering D., Moog O., Sandin L. \& Verdonschot P.F.M. 2004. - Overview and application of the AQEM assessment system. Hydrobiologia, 516, 1-20.

Hildrew A.G., Dobson M.K., Groom A., Ibbotson A., Lancaster J. \& Rundle S.D. 1991. - Flow and retention in the ecology of stream invertebrates. Verh. Internat. Verein. Limnol., 24, 1742-1747.

Johnson R.K. 1998 - Spatiotemporal variability of temperate lake macroinvertebrate communities: detection of impact. Ecol. Appl., 8, 61-70.

Lake P.S. 2000. - Disturbance, patchiness, and diversity in streams. J. N. Am. Benthol. Soc., 19, 573-592.

Li J., Herlihy A., Gerth W., Kaufmann P., Gregory S., Urquhart S. \& Larsen D.P. 2001. - Variability in stream macroinvertebrates at multiple spatial scale. Freshwater Biol., 46, 87-97.

Manly B.J.F. 1991. - Randomisation and Monte Carlo Methods in Biology. Chapman \& Hall, New York

Marchant R. 1999. - How important are rare species in aquatic ecology and bioassessment? A comment to conclusions of Cao et al. 1999. Limnol. Oecanogr., 44, 1840-1841.

Marchant R. 2002. - Do rare species have any place in multivariate analysis for bioassessment? J. N. Am. Benthol. Soc., 21, 311-313.

Minshall G.W. 1988. - Stream ecosystem theory: a global perspecti- ve? J. N. Am. Benthol. Soc., 7, 263-288.

Muotka T. \& Laasonen P. 2002. - Ecosystem recovery in restored headwater streams: the role of enhanced leaf retention. J. Appl. Ecol., 39, 145-156.

Murphy J.F., Giller P.S. \& Horan M.A. 1998. - Spatial scale and aggregation of stream macroinvertebrates associated with leaf packs. Freshwater Biol., 39, 325-337.

Nijboer R.C. \& Schmidt-Kloiber A. 2004. - The effect of excluding taxa with low abundances or taxa with small distribution ranges on ecological assessment. Hydrobiologia, 516, 347-363.

Noda T. 2004. - Spatial hierarchy approach in community ecology: a way beyond high context-dependency and low predictability in local phenomena. Population Ecol., 46, 105-117.

Nógrádi S. \& Uherkovich Á. 1999. - Protected and threatened caddisflies (Trichoptera) of Hungary. Proc. 9th International Symposium on Trichoptera, 291-297.

Ostermiller, J.D. \& Hawkins C.P. 2004. - Effects of sampling error on bioassessments of stream ecosystems: application to RIVPACS-type models. J. N. Am. Benthol. Soc., 23, 363-382.

Palmer M.A., Ambrose R.F. \& Poff N.L. 1997. - Ecological theory and community restoration ecology. Restoration Ecol., 5, 291300

Podani J. 2000. - Introduction to the exploration of multivariate biological data. Backhuys, Leiden, The Netherlands

Sandin L. \& Johnson R.K. 2004. - Local, landscape and regional factors structuring benthic macroinvertebrate assemblages in Swedish streams. Landscape Ecol., 19, 501-514.

Schmera D. 2003. - Assessing stream dwelling caddisfly assemblages (Insecta: Trichoptera) collected by light traps in Hungary. Biodiv. Conserv., 12, 1175-1191.

Schmera D. 2004. - Spatial distribution and coexistence patterns of caddisfly larvae (Trichoptera) in a Hungarian stream. Internat. Rev. Hydrobiol., 89, 51-57.

Schmera D. \& Eros T. 2004. - Effect of riverbed morphology, stream order and season on the structural and functional attributes of caddisfly assemblages (Insecta: Trichoptera). Ann. Limnol. - Int. J. Lim., 40, 193-200.

Schmera D. \& Kiss O. 2004. - A new measure of conservation value combining rarity and ecological diversity: a case study with light trap collected caddisflies (Insecta: Trichoptera). Acta Zool.Acad. Sci. Hungaricae, 50, 195-210.

Statzner B. 1981. - A method to estimate the population size of benthic macroinvertebrates in streams. Oecologia, 51:, 157-161.

Statzner B., Hoppenhaus K., Arens M.-F. \& Richoux P. 1997. - Reproductive traits, habitat use and templet theory: a synthesis of word-wide data on aquatic insects. Freshwater Biol., 3, 109-135.

Statzner B., Gore J.A. \& Resh V.H. 1998. - Monte Carlo simulations of benthic macroinvertebrate populations: estimates using random, stratified, and gradient sampling. J. N. Am. Benthol. Soc. 17, 324-337.

Townsend C.R. 1989. - The patch dynamics concept of stream community ecology. J. N. Am. Benthol. Soc., 8, 36-50.

Townsend C.R., Doledec S., Norris R., Peadock K. \& Arbuckle C. 2003. - The influence of scale and geography on relationships between stream community composition and landscape variables: description and prediction. Freshwater Biol., 48, 768-785.

Townsend C.R., Downes B.J., Peacock K. \& Arbuckle C.J. 2004. Scale and detection of land-use effects on morphology, vegetation and macroinvertebrate communities of grassland streams. Freshwater Biol., 49, 448-462.

Verdonschot P.F.M. \& Nijboer R.C. 2004. - Towards a multi-metric index for the assessment of Dutch streams using benthic macroinvertebrates. Hydrobiologia, 516, 173-189.

Waringer J. 1987. - Spatial distribution of Trichoptera larvae in the 
sediment of an Austrian mountain brook. Freshwater Biol., 18, 469-482.

Waringer J. \& Graf W. 1997. - Atlas der Österreichischen Köcherfliegenlarven. Fakultas Universitatverlag, Wien

Weigel, B.M., Wang L., Rasmussen P.W., Butcher J.T., Stewart P.M., Simon T.P. \& Wiley M.J. 2003. - Relative influence of variables at multiple spatial scales on stream macroinvertebrates in the Northern Lakes and Forest ecoregion, U.S.A. Freshwater Biol., 48, 1440-1461.
Weigelhofer G. \& Waringer J. 2003. - Vertical distribution of benthic macroinvertebrates in riffles versus runs with differing contents of fine sediment (Weidlingbach, Austria). Int. Rev. Hydrobiol., 88, 304-313.

Wright K.K. \& Li J.L. 2002. - From continua to patches: examining stream continuum structure over large environmental gradients. Can. J. Fish. Aquat. Sci., 59, 1404-1417.

Zar J.H. 1999 - Biostatistical analysis. Fourth Edition. Prentice Hall, New Jersey. 
